\title{
Desinfecção emergencial de galeria pluvial pela aplicação de ácido peracético e sua influência na bacia do rio Brejatuba - Guaratuba - Paraná
}

\author{
Storm drain sewage disinfection by using peracetic acid and hydrogen \\ peroxide, and its impact on Brejatuba basin - Guaratuba - Paraná state, \\ southern brazil
}

\author{
Cleverson Vitorio Andreoli | Cedric Schmitt | Charles Carneiro \\ Fernanda Scuissiatto Mares de Souza | Franciane Pellizzari | Jonas Heitor Kondageski \\ Paulo Henrique Marques
}

Data de entrada: 11/10/2012 | Data de aprovação: 23/04/2013

\begin{abstract}
Resumo
O monitoramento da balneabilidade no litoral paranaense tem evidenciado áreas impróprias para recreação de contato primário pela presença do micro-organismo indicador Escherichia coli. Uma das áreas impróprias consiste num trecho localizado na Praia Central de Guaratuba, onde desagua o rio Brejatuba, atualmente muito contaminado devido aos lançamentos irregulares de esgoto, pelas galerias de águas pluviais. Visando à minimização do impacto deste rio na balneabilidade executou-se esta pesquisa com o objetivo de avaliar a desinfecção pela aplicação de um agente oxidante, o ácido peracético. Concluiu-se que o desinfetante apresentou eficácia na redução do índice de E. coli na foz do rio Brejatuba, não tendo sido observadas alterações relevantes nos parâmetros físico-químicos monitorados. Assim, o tratamento do rio Brejatuba promoveu melhoria nas condições de balneabilidade, reduzindo a concentração do indicador de $10^{3} \mathrm{NMP} / 100 \mathrm{~mL}$ para valores próximos a zero.
\end{abstract}

Palavras-chave: Balneabilidade; desinfecção; ácido peracético.

\begin{abstract}
The Paraná coastal area, specifically Central Beach, Guaratuba, has been demonstrated to be inappropriate for recreation purposes due to Escherichia coli high densities. This site receives effluents from Brejatuba river, a contaminated river where the sewage originated in the Brejatuba basin is inputted irregularly. This paper aims to evaluate the outfall Brejatuba river disinfection using peracetic acid, considered to be a strong disinfectant. The disinfectant was effectively in reducing Escherichia coli densities for the Brejatuba river; no important change on physical - chemical parameters related on water quality was detected; as a final result we observed that the Escherichia coli density on the Central Beach was strongly reduced.
\end{abstract}

Key-words: Bathing water beach; disinfection; peracetic acid. 


\section{Introdução}

O monitoramento da balneabilidade no litoral paranaense, segundo a Resolução CONAMA 274/2000 (Brasil, 2000), tem evidenciado áreas impróprias para recreação de contato primário devido à presença do micro-organismo indicador Escherichia coli. Atribui-se a contaminação das praias ao lançamento irregular de efluentes domésticos em galerias de águas pluviais, canais e rios, os quais deságuam diretamente nas praias.

Um dos pontos que apresenta problemas com relação à balneabilidade consiste na Praia Central, no município de Guaratuba, estado do Paraná. Esta praia, uma das mais freqüentadas por veranistas em Guaratuba, recebe a contribuição do rio Brejatuba, o qual freqüentemente apresenta elevadas concentrações de E. coli, o que acaba por tornar a praia imprópria para banho. A bacia hidrográfica deste rio, com área de 80 ha, contempla 1.620 ligações de água, possuindo somente 96 economias não atendidas por ligações de esgoto, o que indica que apenas $6 \%$ são potenciais poluidores do rio Brejatuba. Ainda assim, as economias que se ligaram a rede, mas não desativaram as fossas sépticas continuam contribuindo com seu efluente diretamente pela rede pluvial ou pelo lençol freático, que nesta região encontra-se em um nível relativamente alto. Assim, as intervenções de saneamento (como implantação e manutenção de rede coletora de esgoto) terão falsa eficácia e/ou somente possíveis de ser avaliadas em longo prazo.

Visando a minimização da exposição humana aos patógenos de veiculação hídrica, avaliou-se o tratamento de desinfecção das águas residuárias contaminadas. Um sistema ideal de desinfecção deve garantir uma inativação máxima de micro-organismos patógenos, a exemplo do indicador bacteriano Escherichia coli, ou atender aos limites de qualidade relacionados ao uso pretendido. Relevam-se também a não geração de subprodutos indesejáveis e tóxicos aos seres humanos ou à biota aquática, além de apresentar viabilidade econômica (USEPA, 1999a). Caso o residual apresente esta característica de toxicidade, ele deverá ser removido.

Nos últimos anos, o ácido peracético (PAA) tem sido usado como um desinfetante alternativo aos produtos clorados. O produto "ácido peracético" é comercializado como solução estabilizada composta por peróxido de hidrogênio, ácido acético e ácido peracético, em concentrações variadas.
É reconhecido há alguns anos como agente bactericida, fungicida e esporicida de alta eficiência em diversos setores: hospitais, equipamentos de laboratórios médicos, agricultura, desinfecção de efluentes urbanos, dentre outros. Em estações de tratamento de esgoto tem sido utilizado para reduzir o número de micro-organismos fecais (tanto de origem humana quanto de origem animal), visando reúso ou adequação aos parâmetros de lançamento em países como Itália, Reino Unido, Estados Unidos e França. De acordo com KOIVUNEN e HEINONEN-TANSKI (2005), na Itália várias estações de tratamento de esgoto já utilizam ácido peracético em larga escala. A desinfecção com esse agente torna-se competitiva para efluentes secundários e terciários se os limites microbiológicos para coliformes totais e fecais forem 100 a 1000 UFC/100 mL. Em efluentes terciários, valores $<10$ a 100 UFC/100 $\mathrm{mL}$ também podem ser alcançados.

De acordo com DANIEL (2001), o ácido peracético - cujos produtos resultantes da decomposição são peróxido de hidrogênio, oxigênio e ácido acético - demonstra ser altamente competitivo em relação ao cloro ou ozônio. Este ácido é um forte desinfetante com amplo espectro de atividade antimicrobiana sendo utilizado em diversas indústrias, incluindo a de processamento de alimentos, bebidas, medicamentos, fármacos, têxtil, e de papel. Devido às suas propriedades bactericidas, virucidas, fungicidas e esporicidas, seu uso como desinfetante de efluente doméstico recebe cada vez mais atenção, conforme revisão bibliográfica de SOUZA \& DANIEL (2005). Outras vantagens do ácido peracético como desinfetante de efluentes são: facilidade de implementação de tratamento (sem a necessidade de elevado investimento), alta solubilidade, largo espectro de atividade mesmo na presença de matéria orgânica heterogênea, ausência de residual ou subprodutos tóxicos e/ou mutagênicos, abatimento de residual desnecessário, baixa dependência do $\mathrm{pH}$ e curto tempo de contato (KITIS, 2004).

Conforme constatado por VESCHETTI et al. (2003), o efeito biocida contra coliformes totais e fecais do ácido peracético foi similar ao hipoclorito de sódio. Entretanto, nas amostras de esgoto tratado com ácido peracético não ocorreu variação significativa no teor de compostos orgânicos halogenados, enquanto que na desinfecção com hipoclorito o incremento foi proporcional à dose aplicada. Segundo BAILEY (2011), o ácido 
peracético é uma escolha interessante quando o estudo envolve a mistura do mesmo em água do mar, uma vez que a degradação resulta em subprodutos não tóxicos neste meio.

Os resultados do ensaio de desinfecção com ácido peracético realizado por SOUZA \& DANIEL (2005) sugere efetiva inativação dos micro-organismos E. coli, colífagos e $C$. perfringes, mesmo na presença de elevada concentração de matéria orgânica. Para $5,0 \mathrm{mg} / \mathrm{L}$ de ácido peracético e 15 minutos de contato, há inativação de $E$. coli maior que $1 \times 10^{6}$. Ainda segundo DANIEL (2001), o ácido peracético apresenta baixa toxicidade, contudo pode ser extremamente irritante à pele, aos olhos e ao trato respiratório se a concentração for elevada. O contato da pele ou dos olhos com a solução de ácido peracético a $40 \%$ pode causar queimaduras. Não há registros na literatura de que o ácido peracético seja cancerígeno ou apresente toxicidade na reprodução e no desenvolvimento humano. Porém, há evidências de que esse composto seja cancerígeno fraco a ratos.

Segundo ECETOC (2001), apenas soluções de ácido peracético com concentração maior ou igual a $3.500 \mathrm{mg} / \mathrm{L}$ apresentam efeito irritante à derme. Assim, a Agência de Proteção Ambiental Norte-Americana (USEPA, 1999b) já apresenta o ácido peracético como alternativa no tratamento de vazão excedente à capacidade das estações de tratamento de águas residuárias, ou rede coletora única de águas pluviais e esgoto sanitário. Gasi et al. (1995) apud DANIEL (2001), constataram que a concentração de oxigênio dissolvido (OD) num efluente tratado com este produto manteve-se acima da concentração de saturação, devido à decomposição do ácido peracético em peróxido de hidrogênio $\left(\mathrm{H}_{2} \mathrm{O}_{2}\right)$, e deste em oxigênio e água.

Apresentados os problemas de balneabilidade na Praia Central de Guaratuba /PR, bem como o potencial de desinfecção do ácido peracético, o presente estudo visa avaliar a redução da concentração de E. coli na foz do rio Brejatuba (o qual deságua na Praia Central de Guaratuba-PR) devido a descontaminação microbiológica da galeria pluvial afluente a este rio, a qual recebe contribuição irregular de esgoto sanitário. Esta descontaminação da galeria pluvial, por sua vez, ocorre por meio da aplicação do desinfetante ácido peracético.

É válido ressaltar que esta proposta de desinfecção da galeria pluvial afluente ao rio Breja- tuba consiste numa solução emergencial, e não definitiva, para equacionar o problema da balneabilidade na Praia Central de Guaratuba/PR, uma vez que uma solução sustentável e definitiva envolverá, obrigatoriamente, o saneamento ambiental na bacia do Brejatuba.

\section{Objetivo Geral}

Este estudo visa a avaliar a redução da concentração do micro-organismo Escherichia coli na foz do rio Brejatuba, município de Guaratuba/ $\mathrm{PR}$, após a aplicação de ácido peracético em uma galeria de água pluvial afluente a este rio, e mensurar os impactos físicos, químicos e biológicos na qualidade da água.

\section{Metodologia}

O rio Brejatuba está localizado na cidade litorânea de Guaratuba, Estado do Paraná, e apresenta sua foz na ponta esquerda da Praia Central, próximo ao Morro do Cristo (Figura 1 e 2). A água deste rio, contaminada por esgoto doméstico, ao se juntar à água da praia eventualmente introduz micro-organismos patogênicos, dos quais a E. coli é um indicador, pondo em risco a saúde dos banhistas que se utilizam da Praia Central.

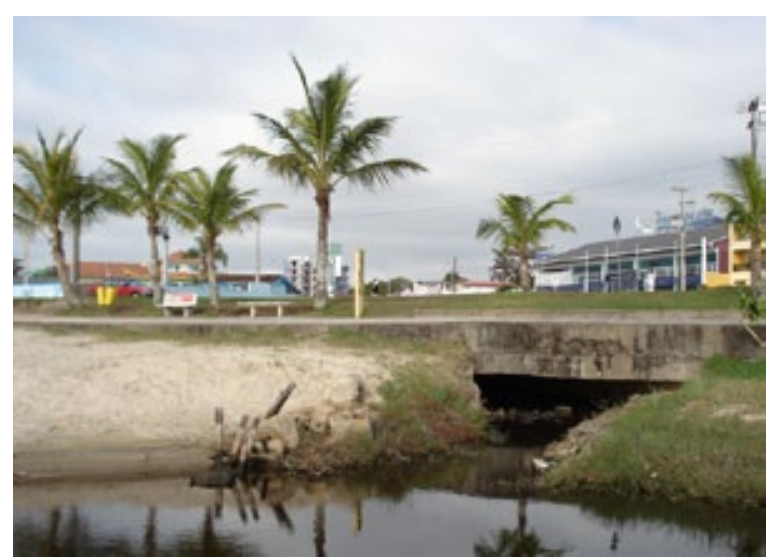

Figura 1- Foto ilustrativa da foz do rio Brejatuba

Desta forma, por meio desta pesquisa objetivou-se reduzir a concentração de E. coli na foz do rio Brejatuba, pela aplicação do desinfetante ácido peracético numa galeria de água pluvial, irregularmente contaminada com esgoto, e que desemboca no rio Brejatuba. Esta aplicação foi realizada diretamente no ponto da galeria de água pluvial que corresponde ao cruzamento das ruas Londrina e Marechal Deodoro, conforme 


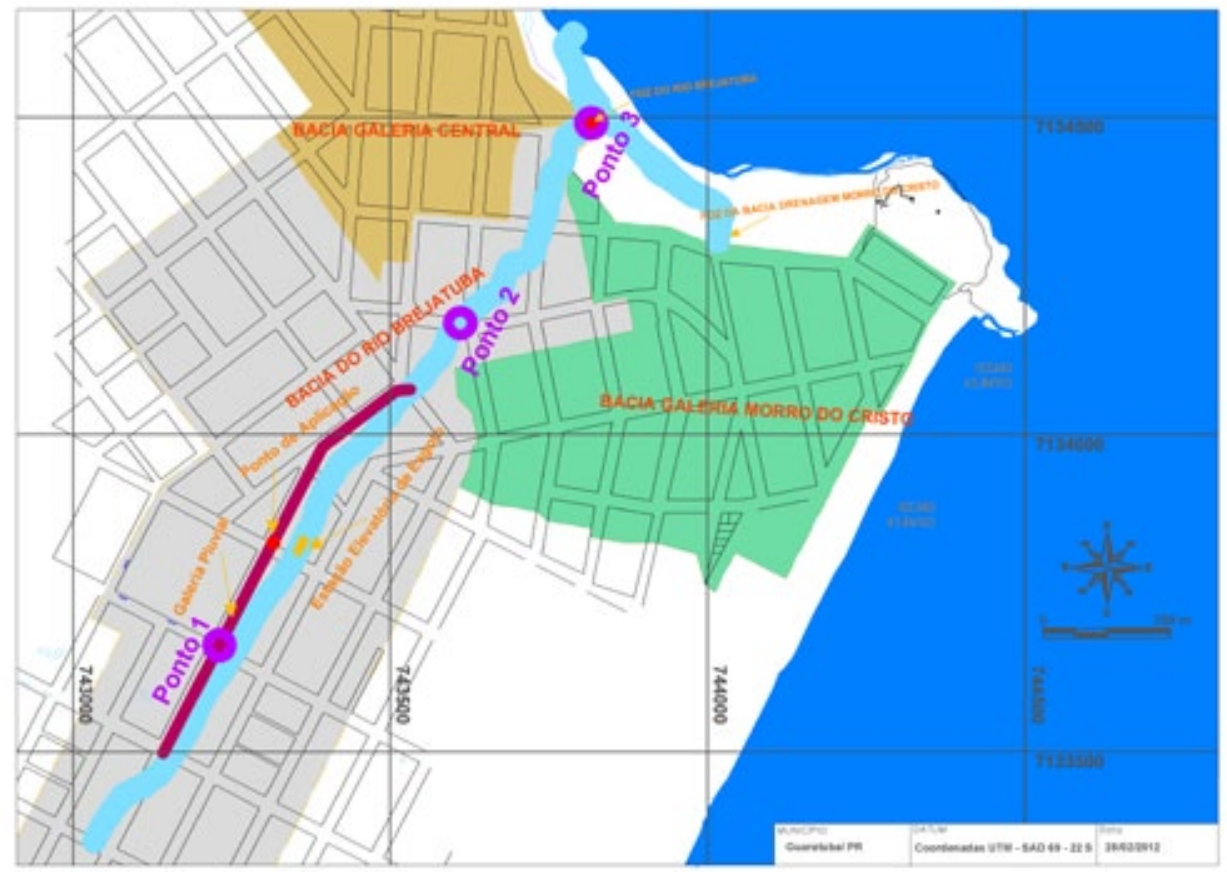

Figura 2- Detalhe do Ponto de Aplicação do desinfetante, da foz do rio Brejatuba,

e dos pontos monitorados.

descrito na Figura 2, próximo ao terreno da estação elevatória de esgoto da Companhia de Saneamento do Paraná, o qual serviu de base para o sistema de aplicação.

Importa destacar que a Prefeitura do Município de Guaratuba concedeu anuência para a realização da pesquisa, seguida pelo Instituto Ambiental do Paraná (IAP), que concedeu autorização ambiental para a pesquisa de desinfecção por meio da aplicação de ácido peracético na bacia do rio Brejatuba.

\section{Estrutura logística e equipamentos de dosagem do ácido peracético}

O controle operacional da aplicação e do sistema como um todo foi realizado diariamente, monitorando-se os teores residuais de ácido peracético e peróxido de hidrogênio ao longo do corpo hídrico nos pontos de amostragem supracitados na Figura 2.

A dosagem do desinfetante peroxidado, que apresenta uma concentração de 15\% de ácido peracético, foi realizada através de bombas dosadoras tipo peristáltica em modo contínuo, instaladas em um box container (Figura 3) localizado no terreno da Estação Elevatória de esgoto, conforme apresentado na Figura 2, o qual serviu como base para o sistema de dosagem. $\mathrm{O}$ produto foi conduzido através de tubulação subterrânea até o ponto mais próximo da galeria pluvial (Figura 2).

As dosagens de ácido peracético situaram-se entre 3 e $22 \mathrm{mg} / \mathrm{L}$; porém, elas não estavam relacionadas à vazão que ocorria no momento da aplicação, sendo as mesmas ajustadas apenas em função do consumo de produto ao longo do corpo hídrico em estudo, conforme será apresentado na seqüência. Cabe ressaltar que as concentrações de desinfetante contempladas neste estudo basearam-se em ensaios de inativação realizados previamente em escala de bancada, com amostra coletada na foz do rio Brejatuba.

A aplicação do ácido peracético foi realizada em duas diferentes etapas, nas quais houve períodos de pico de veranistas na praia de Guaratuba:

Etapa 1: Representado por um período de 11 dias - de 01/09/2009 a 11/09/2009 - o qual compreende o feriado de 7 de Setembro;

Período 2: Representado por um período de 6 dias - de 09/10/2009 a 14/10/2009 - o qual compreende o feriado de 12 de Outubro.

Nestas 2 etapas de testes a aplicação do desinfetante foi realizada de forma contínua, com dosagem variável de acordo com o residual de desinfecção medido ao longo do rio. Assim, caso se verificasse elevada concentração de residual 

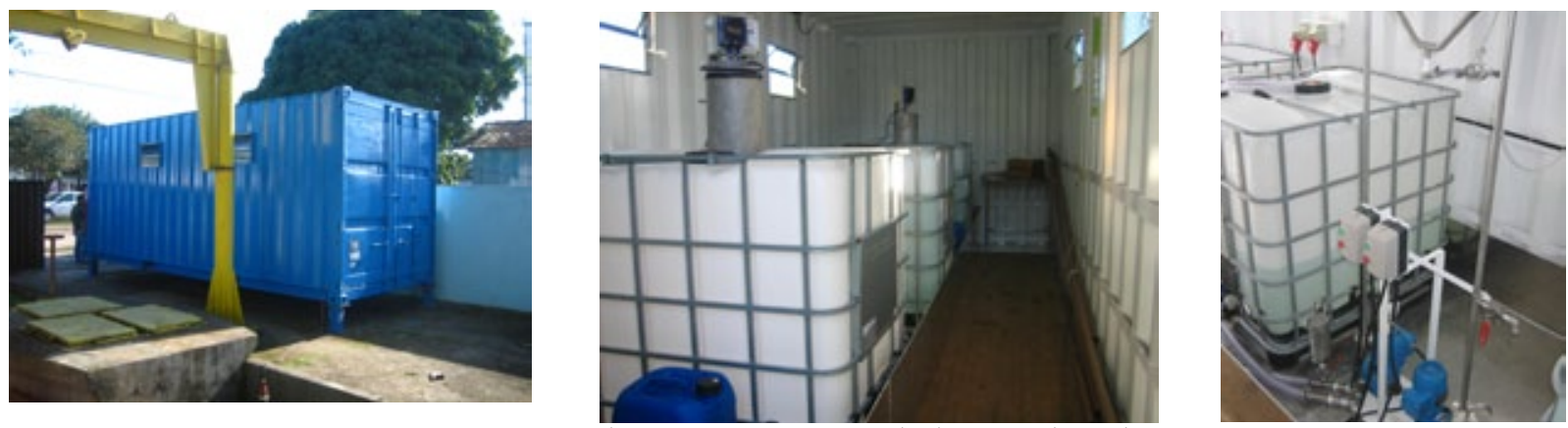

Figura 3- Estrutura, instalações e equipamentos de dosagem de ácido peracético

de desinfecção ao longo do rio, reduzia-se a dosagem de desinfetante no ponto de aplicação. Do contrário, a aplicação era majorada no ponto de aplicação quando não se verificava residual ao longo do rio, pois neste caso entendia-se que o desinfetante foi todo consumido antes de atingir a Praia Central.

\section{Monitoramento das variáveis bióticas e abióticas}

No decorrer das etapas de teste, foram realizadas análises das variáveis bióticas e abióticas na foz do rio Brejatuba (ponto 3), a fim de se avaliar o desempenho do ácido peracético com relação à desinfecção da água que chega à Praia Central de Guaratuba. Além disso, as mesmas variáveis foram analisadas na água da galeria pluvial que recebeu a dosagem de desinfetante (ponto 1), à montante do ponto de aplicação, bem como no rio Brejatuba, à jusante da aplicação e a montante da foz (ponto 2). A Figura 2 apresenta a localização e a identificação dos pontos de amostragem utilizados no monitoramento analítico.

Ensaios de inativação realizados previamente, em escala de bancada, com amostra coletada na própria foz do rio Brejatuba, indicaram dosagens ótimas de ácido peracético que se situaram na faixa 3 a 22 mg/L. A vazão na foz do rio Brejatuba foi medida por meio de molinete de hélice no dia 25/08/2009, anteriormente ao início dos testes referentes à primeira etapa. $\mathrm{O}$ valor obtido nesta medição foi igual a $51 \mathrm{~L} / \mathrm{s}$. Assim, com os dados da faixa de dosagem ótima obteve-se quantidade inicial de ácido peracético a ser aplicada para a vazão inicial de $51 \mathrm{~L} / \mathrm{s}$ : entre $0,5 \mathrm{~kg} / \mathrm{h}$ a $4,0 \mathrm{~kg} / \mathrm{h}$.

Destaca-se que, devido a dificuldades técnicas e financeiras, a vazão no rio não foi monitorada continuamente durante as 2 etapas de testes, assim, apesar da vazão inicialmente estimada na foz $(51 \mathrm{~L} / \mathrm{s})$ ter variado temporalmente devido a fatores como precipitação e aumento popula- cional no período de feriado, a série de vazão durante o período de aplicação não era conhecida. Portanto, a quantidade de desinfetante lançada na galeria pluvial não pôde ser atrelada à vazão na foz do rio.

Uma alternativa a esta dificuldade consistiu em atrelar a quantidade de desinfetante a ser aplicado na galeria pluvial ao residual de desinfecção (constituído por ácido peracético e, eventualmente, peróxido de hidrogênio, um subproduto do primeiro), o qual foi monitorado ao longo do rio Brejatuba, nos pontos 2 e 3. Por exemplo, caso o residual de desinfetante monitorado em alguns dos pontos a jusante da aplicação fosse igual a zero, concluía-se que todo o desinfetante foi consumido até chegar ao respectivo ponto, portanto, a quantidade de ácido peracético lançada na galeria deveria ser elevada até que a foz do rio Brejatuba apresentasse uma quantidade residual de desinfetante (em torno de $5 \mathrm{mg} / \mathrm{L}$ ). Por outro lado, quando a quantidade de residual monitorada na foz estava elevada (maior do que $10 \mathrm{mg} / \mathrm{L}$ ), a quantidade de desinfetante aplicado era reduzida.

A aplicação de ácido peracético foi controlada desta forma, baseada no residual nos pontos 2 e 3 (foz). O monitoramento do residual e, eventualmente, o ajuste na dosagem do desinfetante, realizava-se em média 2 vezes ao dia, principalmente quando se observava descontinuidade clara na vazão, como períodos chuvosos.

Para o monitoramento dos residuais de desinfecção foram utilizadas metodologia Merck, por fitas colorimétricas Merckoquant ${ }^{\circledR}$ e fitas Reflectoquant ${ }^{\circledR}$ analisadas em equipamento RQFlex Plus. Respectivamente, as faixas de quantificação dos métodos são 5 a 50 mg/L e 1,0 a 22,5 mg/L.

Quanto às análises microbiológicas, avaliou-se o micro-organismo indicador de balneabilidade Escherichia coli, conforme preconizado na Re- 
solução CONAMA 274/2000 (Brasil, 2000). A metodologia aplicada foi Enzima Substrato em cartelas, com reagente colilert ${ }^{\circledR}$ e procedimento IDEXX/Quanti-tray ${ }^{\circledast}$ A instituição responsável pela execução analítica foi a Faculdade Estadual de Filosofia, Ciências e Letras de Paranaguá (FAFIPAR), sendo o trabalho realizado pelo Laboratório de Qualidade de Água do Mar (Laquamar).

Dentre as variáveis físico-químicas, foram selecionadas temperatura da água, $\mathrm{pH}$, condutividade elétrica, material particulado em suspensão, turbidez, oxigênio dissolvido. A quantificação destas variáveis foi realizada nos 3 pontos principais ao logo do rio Brejatuba (apresentados na Figura 2), além de 3 pontos intermediários, localizados entre os pontos principais. Os pontos intermediários não estão indicados na Figura 2 pelo fato de não representarem o foco do trabalho, servindo apenas como apoio para a interpretação das variáveis físico-químicas. A coleta de amostras ocorreu apenas na Etapa 1, com freqüência diária, durante 11 dias consecutivos.

A quantificação das variáveis microbiológicas foi realizada nos pontos apresentados na Figura 2, em freqüência diária, ao longo de 13 dias consecutivos na Etapa 1 (01/09/2009 a 13/09/2009) e 8 dias consecutivos na Etapa 2 (09/10/2009 a 16/10/2009). Observa-se que o período de monitoramente microbiológico se estendeu 2 dias além do período de aplicação, com o objetivo de avaliar o retorno do sistema às condições normais depois de cessada a aplicação do desinfetante.

Para a avaliação ecotoxicológica, utilizou-se a bactéria luminescente Vibrio fischeri como micro-organismo indicador, em procedimento realizado pelo laboratório de ecotoxicologia do Instituto Ambiental do Paraná. A avaliação abordada neste parâmetro tem como princípio a determinação de toxicidade aguda através da inibição da luminescência, segundo a NBR 15411.3 (2006). As análises foram executadas em amostras coletadas nos dias 01/09/2009, pré-aplicação do agente desinfetante, e 09/09/2009, durante o período de aplicação do produto, referente à Etapa 1.

\section{Resultados e discussões}

\section{Análises Microbiológicas - Etapa 1}

A Tabela 1 apresenta as concentrações de E. coli monitoradas diariamente durante o intervalo de 13 dias referente à primeira etapa de teste, a qual abrange o feriado de 7 de Setembro. Os resultados são apresentados para o Ponto 1, localizado na galeria pluvial, a

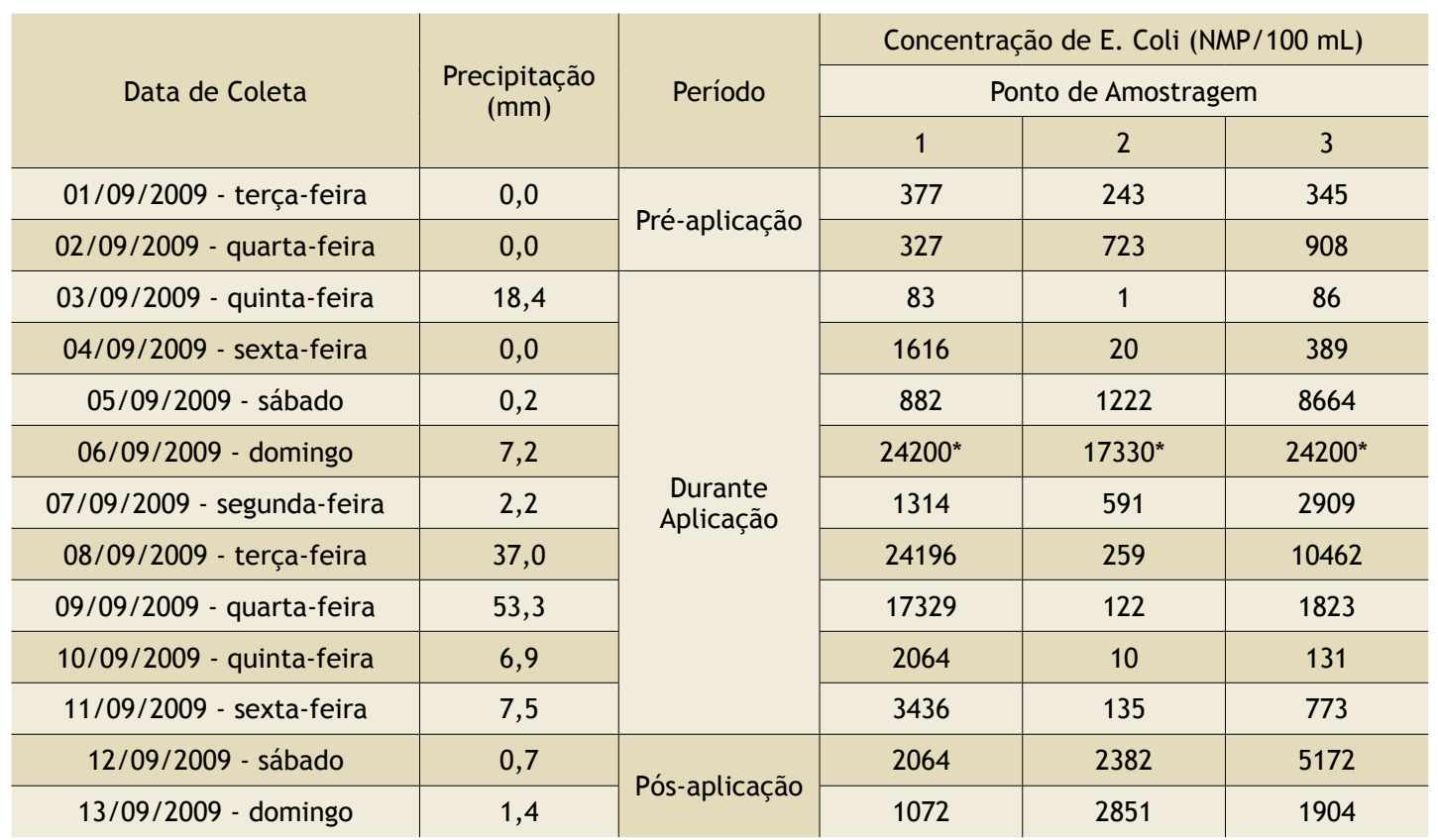

* Neste dia não houve aplicação do desinfetante devido a problemas técnicos com a bomba dosadora.

Tabela 1- Resultados analíticos referentes ao monitoramento microbiológico de E. coli - Etapa 1. 


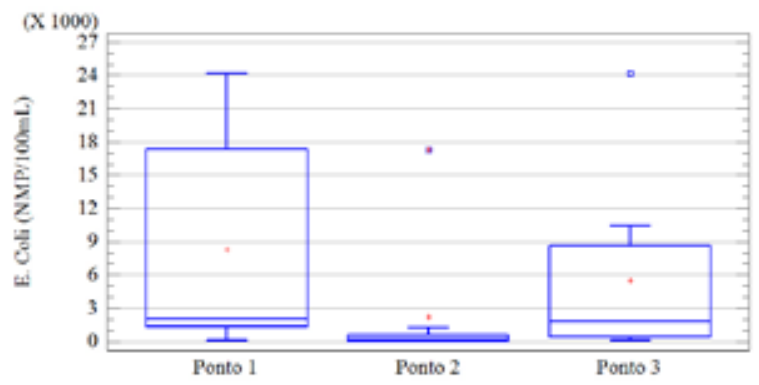

Figura 4- "Box Plot" das concentrações de E. coli nos Pontos 1 (na galeria pluvial, à montante do ponto de aplicação do ácido peracético), 2 (no rio Brejatuba, à jusante da confluência com a galeria pluvial) e 3 (na foz do rio Brejatuba), para o período "Durante aplicação do desinfetante" - Etapa 1- com dosagem de $5 \mathrm{mg} / \mathrm{L}$

montante do ponto de aplicação do desinfetante; Ponto 2, localizado no rio Brejatuba, a jusante da confluência com a galeria pluvial; Ponto 3, na foz do rio Brejatuba (conforme apresentado na Figura 2).

Com base nos resultados verificados ao longo da aplicação realizada na Etapa 1 (Tabela 1), observa-se um incremento nos índices de E. coli para o Ponto 1 (a montante da aplicação) durante o final de semana (sábado e domingo) e feriado propriamente dito, quando comparados ao período pré-aplicação. Atribuiu-se esta elevação da contaminação microbiológica ao efeito combinado de 2 fatores, a saber: aumento da densidade populacional no período do feriado (entre os dias 04/09/2011 e 09/09/2011) devido à chegada de grande número de turistas, mais do que dobrando a população local, o que, por sua vez, eleva a carga de esgoto doméstico lançada na galeria; elevação, neste período, do volume precipitado na bacia, o que aumenta, num primeiro momento, a contribuição de carga difusa de poluente para o sistema hídrico.

Focando apenas no período "Durante aplicação do desinfetante" (Tabela 1), calculou-se que as medianas das concentrações de E. coli nos Pontos 1,2 e 3 foram, respectivamente, 2.034, 135 e $1.823 \mathrm{NMP} / 100 \mathrm{~mL}$, conforme apresentado na Figura 4.

Aplicando o teste de hipótese não paramétrico de Wilcoxon pode-se afirmar, com um nível de significância de $5 \%$, que houve redução na mediana da concentração de E. coli entre o ponto 1 e o ponto 2. Além disso, observa-se que esta redução foi de aproximadamente 90\% entre es- tes pontos.

Por outro lado, ao comparar o ponto 2 com a foz do rio Brejatuba (Ponto 3), percebe-se que a concentração de E. coli aumentou, fato corroborado pelo teste de hipótese não paramétrico de Wilcoxon, com um nível de significância de 5\%.

A Tabela 2 apresenta os resultados das análises referentes aos residuais de desinfecção com ácido peracético para a Etapa 1 .

Por meio da análise das tabelas 1 e 2 e Figura 4 pode-se concluir que a aplicação de ácido peracético foi determinante para reduzir a concentração de E. coli, fato confirmado pela redução do valor do parâmetro entre o ponto 1 (à montante da aplicação) e ponto 2 (à jusante da aplicação). Porém, o efeito de inativação do micro-organismo indicador ficou limitado espacialmente até o ponto 2 , uma vez que na foz (ponto 3 ) observou-se novamente a elevação do indicador. Conforme dados presentes na Tabela 2, sugere-se que a ausência de residual de desinfetante no ponto 3 tenha permitido a sobrevivência dos micro-organismos; ou seja, até o ponto 2 o desinfetante desempenhou a função de reduzir a concentração de E. coli

\begin{tabular}{c|c|c|c}
\multirow{2}{*}{ Data de Coleta } & Dosagem & \multicolumn{2}{|c}{$\begin{array}{c}\text { Residual } \\
\text { de ácido } \\
\text { peracético } \\
(\mathrm{mg} / \mathrm{L})^{* *}\end{array}$} \\
\cline { 3 - 4 } & $\begin{array}{c}\text { pe ácido } \\
\text { peracético } \\
(\mathrm{mg} / \mathrm{L})^{*}\end{array}$ & $\begin{array}{c}\mid c \\
\text { Ponto de } \\
\text { Amostragem }\end{array}$ \\
\cline { 3 - 4 } & & 2 & 3 \\
\hline $03 / 09 / 2009$ - quinta-feira & 5 & 4,8 & $<1$ \\
\hline $04 / 09 / 2009$ - sexta-feira & 5 & $<1$ & $<1$ \\
\hline $05 / 09 / 2009$ - sábado & 5 & 2,2 & $<1$ \\
\hline $06 / 09 / 2009$ - domingo & $\left.-{ }^{* * *}\right)$ & $<1$ & $<1$ \\
\hline $07 / 09 / 2009$ - segunda-feira & 5 & $<1$ & $<1$ \\
\hline $08 / 09 / 2009$ - terça-feira & 5 & 1,9 & $<1$ \\
\hline $09 / 09 / 2009$ - quarta-feira & 11 & $<1$ & $<1$ \\
\hline $10 / 09 / 2009$ - quinta-feira & 11 & 1,8 & 1,5 \\
\hline $11 / 09 / 2009$ - sexta-feira & 11 & $<1$ & $<1$ \\
\hline
\end{tabular}

*A dosagem de ácido peracético apresentada na tabela refere-se à vazão de $51 \mathrm{~L} / \mathrm{s}$ (medida no início da pesquisa), a qual não era, necessariamente, igual à vazão efetivamente existente no momento da aplicação do desinfetante.

** Limite de detecção de $1 \mathrm{mg} / \mathrm{L}$

*** Neste dia não houve aplicação do desinfetante devido a problemas técnicos com a bomba dosadora.

Tabela 2- Resultados analíticos referentes aos residuais de ácido peracético - Etapa 1 
sendo, para tal, praticamente consumido em sua totalidade. Porém, após este ponto, a quantidade de desinfetante que ainda restou no rio não foi suficiente para manter o efeito de eliminação dos micro-organismos que foram sendo aportados ao longo do rio, entre os pontos 2 e 3 . Este fato pode ser confirmado ao se observar que, conforme apresentado na Tabela 2, na foz do rio Brejatuba o desinfetante já havia sido completamente consumido (residual abaixo do limite de detecção em quase todos os dias amostrados).

Tal constatação sugere que a dosagem de ácido peracético na galeria pluvial afluente ao rio Brejatuba não foi suficiente para manter o efeito de desinfecção até o ponto 3 . Ou seja, não foi possível verificar melhoria da qualidade da água na foz do rio Brejatuba.

Analisando as Tabelas 1 e 2, observa-se que no dia 6 não houve dosagem do agente desinfetante, o que resultou, obviamente, em ausência de residual de desinfecção, além de elevada concentração de E. coli nos pontos 2 e 3. Por outro lado, no dia 10 aplicou-se dosagem de $11 \mathrm{mg} / \mathrm{L}$ de ácido peracético; esta dosagem foi alta o suficiente para que houvesse desinfetante ao longo de todo o rio (residual de ácido peracético igual a 1,5 $\mathrm{mg} / \mathrm{L}$ no ponto 3) e, desta forma, pudesse agir na inativação dos micro-organismos, reduzindo, neste dia, a contagem de E. coli na foz do Brejatuba. Esta constatação corrobora a importância da dosagem de desinfetante no atendimento do objetivo de redução do valor do parâmetro microbiológico na foz do rio Brejatuba.

Assim, para a primeira etapa de testes pode-se afirmar que a aplicação do desinfetante foi efetiva na redução da concentração de E. coli entre os pontos 1 e 2 , porém, este efeito não foi observado no ponto 3 , a foz do rio Brejatuba, onde efetivamente objetivou-se reduzir a contagem de micro-organismo indicador E. coli.

\section{Análises Microbiológicas - Etapa 2}

Considerando os resultados obtidos durante a primeira etapa de testes, foram sugeridas duas possibilidades para adequação na aplicação do desinfetante, visando à redução microbiana na foz do rio Brejatuba. Primeiramente, a possibilidade de aumentar a dosagem de produto a fim de se garantir o efeito até o último ponto de coleta (ponto 3), ou reduzir a distância entre o ponto de aplicação e o ponto 3. Por motivos operacionais, de segurança e técnicos, consensuou-se a favor de um aumento na dosagem de desinfetante.

A Tabela 3 apresenta as concentrações de E. coli monitoradas diariamente durante o intervalo de 8 dias referentes à segunda etapa de teste, a qual abrange o feriado de 12 de Outubro. Os resultados são apresentados para o ponto 1, localizado na galeria pluvial, a montante do ponto de aplicação do desinfetante; ponto 2, localizado no rio Brejatuba, a jusante da confluência com a galeria pluvial; ponto 3, na foz do rio Brejatuba.

No dia 10/10/2009 ocorreu uma parada inesperada da bomba dosadora, motivo pelo qual nota-se um aumento nos valores de E. coli nos pontos 2 e 3 em comparação com as outras datas nas quais houve aplicação de ácido peracético.

Focando apenas no período "Durante aplica-

\begin{tabular}{|c|c|c|c|c|c|}
\hline \multirow{3}{*}{ Data de Coleta } & \multirow{3}{*}{$\begin{array}{l}\text { Precipitação } \\
(\mathrm{mm})\end{array}$} & \multirow{3}{*}{ Período } & \multicolumn{3}{|c|}{ Concentração de E. Coli (NMP/100 mL) } \\
\hline & & & \multicolumn{3}{|c|}{ Ponto de Amostragem } \\
\hline & & & 1 & 2 & 3 \\
\hline 09/10/2009 - sexta-feira & 0 & \multirow{6}{*}{$\begin{array}{c}\text { Durante } \\
\text { Aplicação }\end{array}$} & 393 & 10 & 1 \\
\hline 10/10/2009 - sábado & 0,2 & & $218^{*}$ & $2419^{*}$ & $1842^{*}$ \\
\hline $11 / 10 / 2009$ - domingo & 0,2 & & 1439 & 1 & 1 \\
\hline $12 / 10 / 2009$ - segunda-feira & 8,6 & & 2419 & 1 & 1 \\
\hline 13/10/2009 - terça-feira & 0 & & 389 & 1 & 2 \\
\hline $14 / 10 / 2009$ - quarta-feira & 0 & & 2143 & 1 & 7 \\
\hline $15 / 10 / 2009$ - quinta-feira & 22,3 & \multirow{2}{*}{ Pós-aplicação } & 19863 & 24196 & 24196 \\
\hline $16 / 10 / 2009$ - sexta-feira & 15 & & 5475 & 12997 & 15531 \\
\hline
\end{tabular}

Tabela 3- Resultados analíticos referentes ao monitoramento microbiológico de E. coli - Etapa 2 
ção do desinfetante" (Tabela 3), calculou-se a mediana das concentrações de E. coli, a qual foi igual a $916 \mathrm{NMP} / 100 \mathrm{~mL}$ no ponto 1, e próxima de 0 nos pontos 2 e 3 , conforme apresentado na Figura 5.

Aplicando o teste de hipótese não paramétrico de Mann-Whitney-Wilcoxon pode-se afirmar, com um nível de significância de 5\%, que houve redução na mediana da concentração de E. coli entre o ponto 1 e o ponto 3. Além disso, observa-se que para a maioria das amostras, esta concentração se aproximou de zero na foz do rio Brejatuba.

Durante a segunda etapa de testes, realizada durante o feriado de 12 de Outubro, não houve avaliação do sistema previamente a aplicação do desinfetante, uma vez que as contagens são relativamente baixas quando a densidade populacional refere-se somente aos habitantes nativos da cidade.

Quanto aos valores residuais de ácido peracético, pode-se observar que, ao longo do dia, dosagens constantes do agente desinfetante implicam em diferentes valores residuais. Avaliando os resultados apresentados na Tabela 4, estima-se um

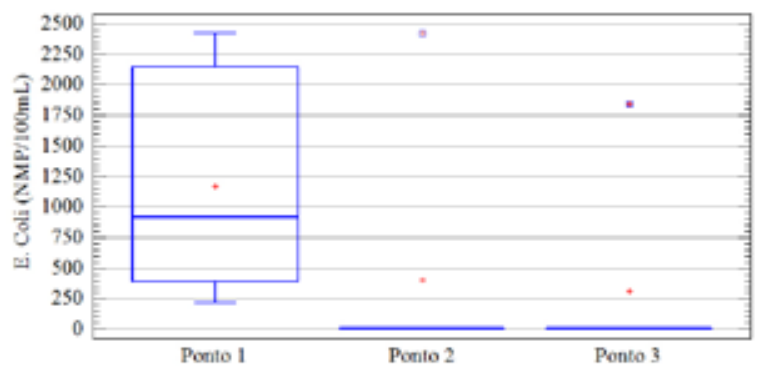

Figura 5- "Box Plot" das concentrações de E. coli nos Pontos 1 (na galeria pluvial, à montante do ponto de aplicação do ácido peracético), 2 (no rio Brejatuba, à jusante da confluência com a galeria pluvial) e 3 (na foz do rio Brejatuba), para o período "Durante aplicação do desinfetante" - Etapa 2

residual aproximado de $\quad 3 \mathrm{mg} / \mathrm{L}$ no ponto 3 quando a dosagem situa-se em $11 \mathrm{mg} / \mathrm{L}$; e aproximadamente $5 \mathrm{mg} / \mathrm{L}$ quando a dosagem é mantida em $22 \mathrm{mg} / \mathrm{L}$. Conforme KOIVUNEN e HEINONEN-TANSKI (2005), o baixo consumo de ácido peracético ocorre em matrizes aquosas de alta qualidade (valores reduzidos de DQO, SS e turbidez). Ou seja, a presença de elevada concen- tração de sólidos suspensos e DQO no efluente pode incrementar significativamente o consumo de ácido peracético, e reduzir a eficiência da desinfecção. Nesse contexto, sugere-se que seja necessário um intervalo de tempo inicial para aclimatação do ecossistema com a ação do produto em dose elevada, no qual haverá uma leve tendência ao maior consumo e suposta oxidação da matéria orgânica acumulada, e no decorrer um retorno à estabilidade. Depois de atingido este equilíbrio, a dosagem aplicada deve ser suficiente para oxidar a matéria orgânica que é lançada continuamente no rio, bem como para inativar os micro-organismos patogênicos.

Desta forma, torna-se relevante mencionar os principais fatores interferentes no mecanismo de ação do ácido peracético e, conseqüentemente, no consumo deste agente desinfetante. Entre eles situam-se o tempo de contato, homogeneização, concentração do agente, temperatura, organismos-alvo e a natureza da matriz de aplicação (matéria carbonácea, metais, $\mathrm{pH}$, sólidos suspensos, série nitrogenada) (METCALF \& EDDY, 2003).

Com base nos resultados microbiológicos verificados nesta $2^{\mathrm{a}}$. etapa de teste, apresentados na Tabela 3, e as dosagens apresentadas na Tabela 4, pode-se concluir que a maior dosagem do agente desinfetante implicou diretamente na redução dos índices de E. coli nos pontos 2 e 3 com relação ao ponto 1 . Ou seja, nesta etapa, atingiu-se o objetivo de reduzir a concentração de E. coli na foz do rio Brejatuba. A ausência de chuvas intensas durante esta etapa do teste possibilitou a eliminação da variável pluviosidade.

Destaca-se que, apesar da verificação da redução de E. coli na foz do rio Brejatuba, deve haver um monitoramento eficaz no trecho de praia adjacente ao rio, com o objetivo de verificar o atendimento aos padrões de balneabilidade, mitigando, desta forma, os riscos associados à balneabilidade.

\section{Ensaios de Ecotoxicidade}

O controle dos impactos ecotoxicológicos para avaliação da toxicidade aguda foi realizado pelo laboratório do Instituto Ambiental do Paraná (IAP) com a bactéria Vibrio fischeri. Os resultados demonstram a ausência de variação entre os dados obtidos antes e depois da aplicação do agente desinfetante. A dosagem de ácido peracético estimada situou-se próxima a $10 \mathrm{mg} / \mathrm{L}$. Na Tabela 5 estão apresentados os valores obtidos. 


\begin{tabular}{|c|c|c|c|}
\hline \multirow{3}{*}{ Data de Coleta } & \multirow{3}{*}{$\begin{array}{l}\text { Dosagem de } \\
\text { ácido peracé- } \\
\text { tico }(\mathrm{mg} / \mathrm{L})^{*}\end{array}$} & \multirow{2}{*}{\multicolumn{2}{|c|}{$\begin{array}{c}\text { Residual de ácido peracético (mg/L) } \\
\text { Ponto de Amostragem }\end{array}$}} \\
\hline & & & \\
\hline & & 2 & 3 \\
\hline 09/10/2009 - sexta-feira - 10:00 & 3 & 5,1 & 2,8 \\
\hline 10/10/2009 - sábado - 10:00 & $0^{* *}$ & $<1,0$ & $<1,0$ \\
\hline 10/10/2009 - sábado - 15:00 & 22 & 21,3 & 5,1 \\
\hline 11/10/2009 - domingo - 10:00 & 22 & 21,4 & 5,6 \\
\hline $11 / 10 / 2009$ - domingo - $16: 30$ & 22 & 21,7 & 7,7 \\
\hline $11 / 10 / 2009$ - domingo - 22:30 & 11 & na & 5,2 \\
\hline $12 / 10 / 2009$ - segunda-feira - 10:00 & 11 & 4,5 & 4,9 \\
\hline $12 / 10 / 2009$ - segunda-feira - $12: 00$ & 11 & 9,3 & 5 \\
\hline $12 / 10 / 2009$ - segunda-feira - $18: 30$ & 11 & na & 2,3 \\
\hline $12 / 10 / 2009$ - segunda-feira - 22:30 & 11 & na & $<1,0$ \\
\hline 13/10/2009 - terça-feira - 10:00 & 20 & na & 5 \\
\hline 13/10/2009 - terça-feira - 15:00 & 20 & na & 2,9 \\
\hline 13/10/2009 - terça-feira - 18:00 & 11 & na & $<1,0$ \\
\hline 13/10/2009 - terça-feira - 22:00 & 11 & na & $<1,0$ \\
\hline $14 / 10 / 2009$ - quarta-feira - 10:00 & 20 & 21 & 2,3 \\
\hline
\end{tabular}

*A dosagem de ácido peracético apresentada na tabela refere-se à vazão de $51 \mathrm{~L} / \mathrm{s}$ (medida no início da pesquisa), a qual não era, necessariamente, igual à vazão efetivamente existente no momento da aplicação do desinfetante

** Bomba Dosadora fora de operação

na: dado não analisado

Tabela 4- Resultados analíticos referentes aos residuais de ácido peracético

- Etapa 1

Destaca-se que no dia 09/09/2009, quando foi coletada amostra para o teste de toxicidade, o residual de desinfecção no ponto coletado estava menor do que 1; este pode ter sido um dos motivos da ausência de toxicidade aguda, ou seja, não havia desinfetante suficiente para propiciar toxicidade à Vibrio fischeri. Desta forma, os resultados não são conclusivos quanto à toxicidade aguda, sendo recomendada a realização de pesquisas específicas para se avaliar a toxicidade do ácido peracético através deste indicador. Porém, como esta avaliação não consistiu no foco do trabalho, não há prejuízo para as conclusões desta pesquisa.

\section{Análises Físico-Químicas - Etapa 1}

Para a interpretação dos resultados das análises físico-químicas procura-se considerar a bacia como um todo, buscando enfatizar as possíveis alterações e riscos ecológicos, mesmo se tratando de um ecossistema urbano, extremamente alterado e eutrofizado.

A) Variáveis não afetadas pelo experimento
Não foram encontradas alterações estatisticamente significativas nas variáveis $\mathrm{pH}$, condutividade elétrica, turbidez e sólidos em suspensão durante todo o processo, antes e depois da aplicação do desinfetante.

\begin{tabular}{|c|c|c|c|} 
PARÂMETRO & AMOSTRA & $\begin{array}{c}01 / 09 / 09 \\
\text { (pré-apli- } \\
\text { cação) }\end{array}$ & $\begin{array}{c}09 / 09 / 09 \\
\text { (durante } \\
\text { aplica- } \\
\text { ção) }\end{array}$ \\
\hline \multirow{2}{*}{$\begin{array}{c}\text { Toxicidade Aguda } \\
\text { para a } \\
\text { bactéria } \\
\text { Vibrio fischeri }\end{array}$} & $\begin{array}{c}\text { Ponto 1 } \\
\text { (montante } \\
\text { aplicação) }\end{array}$ & 1 & 1 \\
\cline { 2 - 4 } & $\begin{array}{c}\text { Ponto 4 } \\
\text { (foz) }\end{array}$ & 1 & 1
\end{tabular}

$F T_{b l}$ - Fator de Toxicidade: menor diluição da amostra na qual não se observa efeito tóxico nos organismos teste. Quanto maior o FTbl, maior a toxicidade da amostra.

$F T_{b l}=1$ - a amostra não apresenta toxicidade aguda.

$F T_{b l}>1$ - a amostra apresenta toxicidade aguda.

Tabela 5- Resultados referentes à toxicidade aguda para Vibrio fischeri 
B) Concentração de Oxigênio Dissolvido

O Oxigênio Dissolvido representou a variável que demonstrou maior alteração nos pontos a jusante da aplicação do produto, especialmente nos dias sem chuva. Em algumas amostras o Oxigênio Dissolvido excedeu o limite de saturação da água (efeito de supersaturação). Entretanto, no ponto 3 (foz) a concentração de oxigênio esteve estabilizada. A Figura 6 demonstra claramente o aumento de OD a jusante da aplicação do produto e gradiente decrescente.

\section{Conclusões}

O uso de Ácido Peracético como agente desinfetante apresentou-se eficaz na redução do índice de E. coli na foz do rio Brejatuba quando as dosagens aplicadas situaram-se entre 10 e 20 $\mathrm{mg} / \mathrm{L}$ (Segunda etapa de testes).

Em relação às variáveis físico-químicas, as alterações visualizadas em alguns parâmetros específicos não foram relevantes, pois se trata de um ecossistema bastante alterado e impactado. Destaca-se que o Oxigênio Dissolvido constituiu a variável mais impactada com a aplicação do ácido peracético.

O consumo de ácido peracético sofre variação ao longo do dia em função da presença de fatores interferentes de origem até então desconhecida, mas que podem estar relacionados com a produção cíclica de esgotos domésticos, bem como eventos de chuva.

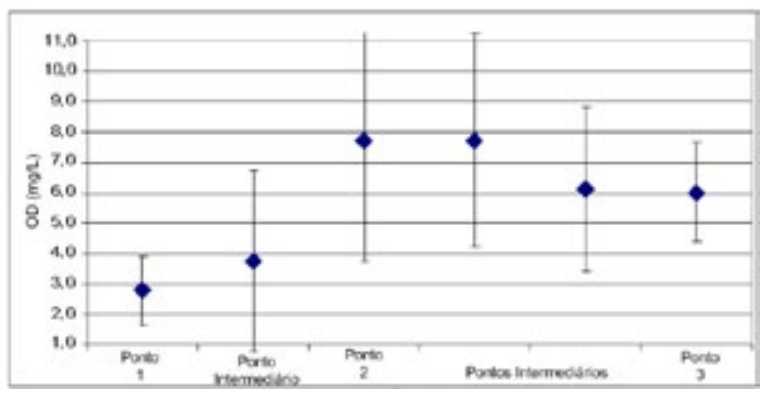

Figura 6- Variação espacial das concentrações de oxigênio dissolvido

Durante a $2^{\mathrm{a}}$ etapa de aplicação foi possível verificar a redução total no índice de E. coli presente na foz do rio Brejatuba, após a dosagem do desinfetante peroxidado.

Considerando os limites propostos pela balneabilidade, conclui-se que o tratamento do corpo hídrico em estudo promove uma melhoria na qualidade microbiológica da água.

A condução do experimento e as análises realizadas não evidenciaram até o presente momento qualquer indício de risco à saúde humana, seja pela exposição ao produto nas concentrações utilizadas, seja pela formação de compostos secundários de natureza tóxica que possam comprometer a balneabilidade.

A dosagem ideal do produto é aquela que não eleva a concentração de oxigênio dissolvido acima do limite de saturação do corpo d'água em nenhum momento, ao mesmo tempo em que se obtém o desejável efeito de desinfecção; assim, minimiza-se a alteração ecológica dos corpos hídricos.

Recomenda-se o esgotamento e a desativação das fossas sépticas existentes na região atendida pela rede de esgoto.

Nas condições experimentais em que a pesquisa foi desenvolvida, conclui-se que o método avaliado é capaz de melhorar as condições sanitárias microbiológicas na foz do rio Brejatuba, sem apresentar riscos à saúde humana.

\section{AGRADECIMENTOS}

Aos Funcionários da Sanepar de Guaratuba, que prestaram apoio técnico e operacional na realização da pesquisa.

Ao laboratório LAQUAMAR, ligado à Faculdade Estadual de Filosofia, Ciências e Letras de Paranaguá (FAFIPAR), onde foram realizadas as análises microbiológicas.

As variáveis físico-químicas foram estudadas pela equipe do Laboratório de Análise Ambiental da UFPR-Litoral, com a participação de estudantes do Curso de Bacharelado em Gestão Ambiental, turma 2006, dentro da programação do Módulo "Gestão Integrada de Bacias Hidrográficas".

\section{Referências bibliográficas} ASSOCIAÇÃO BRASILEIRA DE NORMAS TÉCNICAS. NBR 15411-3: Ecotoxicologia Aquática Determinação do Efeito Inibitório de Amostras de Água sobre a emissão de luz de Vibrio fischeri (Ensaio de Bactéria luminescente) - Parte 3: Método utilizando bactérias liofilizadas. 2006.

BRASIL. Resolução CONAMA no 274 de 29 de Novembro de 2000.

BAILEY, M.M., COOPER, W.J., GRANT, S.B. In situ 
disinfection of sewage contaminated shallow groundwater: A feasibility study. Water Research, no. 45, p. 5641-5653, 2011.

DANIEL, L. A. Processos de desinfecção e desinfetantes alternativos na produção de água potável. PROSAB 2. Ed. RiMa, São Carlos, SP. 2001.

ECETOC. Peracetic Acid (CAS No. 79-21-0) and its Equilibrium Solutions. JACC no.40, 2001.

KITIS, M. Disinfection of wastewater with peracetic acid: a review. Environment International, no. 30, p. 47-55, 2004.

KOIVUNEN, J., HEINONEN-TANSKI, H. Peracetic acid (PAA) disinfection of primary, secondary and tertiary treated municipal wastewaters. Water Research, no. 39, p. 4445-4453, 2005.

METCALF \& EDDY. Wastewater Engineering Treatment and Reuse. McGraw-Hill. 4a ${ }^{\mathrm{a}}$. Edição. 2003.

SOUZA, J.B., DANIEL, L.A. Comparação entre Hipoclorito de Sódio e Ácido Peracético na Inativação de E. coli, colífagos e C. perfringes em Água com Elevada Concentração de Matéria Orgânica. Artigo Técnico. Revista Engenharia Sanitária e Ambiental. ABES, v. 10, nº. 8. 2005.

USEPA. Alternative Disinfectants and Oxidants Guidance Manual. Office of Water. EPA 815-R99-014. Abril, 1999a.

USEPA. Combined Sewer Overflow Technology Fact Sheet - Alternative Disinfection Methods. EPA 832-F-99-033. Setembro, 1999b.

VESCHETTI, E., CUTILLI, D., BONADONNA, L., BRIANCESCO, R., MARTINI, C., CECCHINI, G., ANASTASI, P., OTTAVIANI, M. Pilot-plant comparative study of peracetic acid and sodium hypochlorite wastewater disinfection. Water Research, no. 37, p. 78-94, 2003.

\section{SOBRE OS AUTORES}

Cleverson Vitorio Andreoli (1)

Eng. Agr., Doutor em Meio Ambiente e Desenvolvimento, Professor do Programa de Mestrado em Governança e Sustentabilidade do ISAE e Eng de Pesquisa da Sanepar

Cedric Schmitt

) Técnico em Química Industrial e Administrador com Habilitação em Comercio Exterior. Gestor de Clientes - Peróxidos do Brasil.

Charles Carneiro

Eng. Agr., Mestre em Ciência do Solo e Doutor em Geologia
Ambiental - Geoquímica de Águas, professor PECCA/UFPR e Gerente de Pesquisa da Companhia de Saneamento do Paraná - SANEPAR.

\section{Fernanda Scuissiatto Mares de Souza}

Química Ambiental pela UTFPR e atualmente cursando Engenharia Ambiental na FAE e Mestrado em Ciência e Tecnologia Ambiental pela UTFPR. Responsável Técnica da Alloxy Especialidades Químicas Ltda.

\section{Franciane Pellizzari}

Bióloga, Doutora em Ficologia Marinha pela USP. Docente pesquisadora da Universidade Estadual do Paraná, campus FAFIPAR. Coordenadora do Laboratório de Ficologia e Qualidade de Água Marinha. Paranaguá, PR, Brasil. francianep@ yahoo.com

\section{Jonas Heitor Kondageski}

Engenheiro ambiental formado na Universidade Federal do Paraná, mestrado em Recursos Hídricos e Ambiental pela UFPR. Atualmente trabalha na área de pesquisa da Companhia de Saneamento do Paraná - SANEPAR

\section{Paulo Henrique Marques}

Biólogo, Dr. em Ciências- Ecologia e Recursos Naturais, Professor da UFPR Setor Litoral

(1)Rua Engenheiros Rebouças, 1376; CEP 80.215-900 - Rebouças, Curitiba - Paraná.

Email: c.andreoli@sanepar.com.br 